\title{
Results of long term testosterone replacement therapy in men with abdominal obesity, erectile dysfunction and testosterone deficiency
}

\author{
Fillo $\mathrm{J}^{1}$, Breza $\mathrm{J} \mathrm{Jr}^{5}$, Ondrusova $\mathrm{M}^{2}$, Luha $\mathrm{J}^{3}$, Ondrus $\mathrm{D}^{4}$, Dubravicky $\mathrm{J}^{5}$, Breza $\mathrm{J}^{5}$, Labas $\mathrm{P}^{1}$, \\ Levcikova $\mathrm{M}^{6}$
}

Department of Surgery, Comenius University, Faculty of Medicine, Old Town University Hospital, Bratislava, Slovakia. miskalevcikova@gmail.com

\begin{abstract}
INTRODUCTION: In this article, the authors evaluate subjective and objective results of long testosterone replacement therapy (TRT) and possible risk.

METHODS: In a single center study, the authors treated 69 men with testosterone deficiency syndrome (TDS). The average age was 57.84 years and the follow-up period was 94.62 months. All men had at beginning a complete urological and internal examination. All the men were treated with three-month i.m. injections of 1000 $\mathrm{mg}$ testosterone undecanoate. The men were regularly checked according to the EAU guidelines.

RESULTS: All of the men on treatment felt much better. Weight and waist circumference during monitoring showed a mild improvement. Excellent results were on red blood cells. Glucose, HDL cholesterol, triglycerides had stable values. PSA slightly increased and testosterone was within the normal range. In two men during treatment, we found a prostate cancer (low risk). Bone mineral density (BMD) of lumbar spine revealed a significant improvement.

CONCLUSION: TRT had multiple positive effect on affected men with TDS. Our long-term results showed a long mild improvement during the time. Authors concluded that long term treatment had multiple benefit for affected men (Fig. 11, Ref. 13). Text in PDF www.elis.sk.

KEY WORDS: Testosterone deficiency syndrome, erectile dysfunction, abdominal obesity, metabolic syndrome, testosterone replacement therapy, long term follow up.
\end{abstract}

\section{Introduction}

There is still discussion about the benefits and risks of TRT in men with TDS. In this article, the authors present long term results of TRT in men with TDS and abdominal obesity (AO). Among men with AO, $74.7 \%$ had some grade of erectile dysfunction (ED) and metabolic syndrome (MetS) $53.0 \%$ and only $14 \%$ of these men with AO with waist circumference over $120 \mathrm{~cm}$ had an appropriate testosterone level (over $14 \mathrm{nmol} / \mathrm{l})(1,2)$. Evaluating of TRT is not so simple because lot of signs are subjective. Authors evaluated subjective symptoms with questionnaires and objective

${ }^{1}$ Department of Surgery, Comenius University, Faculty of Medicine, Old Town University Hospital, Bratislava, Slovakia, ${ }^{2}$ St. Elisabeth University of Health and Social Sciences, Bratislava, Slovakia; ${ }^{3}$ Institute of Medical Biology, Genetics and Clinical Genetics, Comenius University, Faculty of Medicine, Bratislava, Slovakia, ${ }^{4} 1$ st Department of Oncology, Comenius University, Faculty of Medicine, St. Elisabeth Cancer institute, Bratislava, Slovakia, ${ }^{5}$ Department of Urology, University Hospital, Bratislava, Slovakia, and ${ }^{6}$ Department of Urology, Sts Cyril and Methodius University Hospital, Bratislava, Slovakia

Address for correspondence: M. Levcikova, MD, Department of Urology, Sts Cyril and Methodius University Hospital, Limbova 5, SK-833 05 Bratislava, Slovakia. laboratory results, weight, waist circumference, BMD. MetS has a higher risk of cardiovascular, diabetic complication and other comorbidities. These men need follow up and prevention to avoid serious complications.

\section{Material and methods}

In a single center study, the authors treated 69 men with TDS. The average age was 57.84 years from 42 to 73 at the time of enter and the follow-up period was 94.62 months. All the men had at the beginning a complete urological and internal examination. Subjective signs were monitored with ageing male scale (AMS) questionnaire, erectile functions were evaluated with international index of erectile functions (IIEF 5) questionnaire, voiding functions were monitored with international prostate symptoms score (IPSS), weight, waist circumference, blood tests: hemoglobin, hematocrit, erythrocytes, HDL cholesterol, triglycerides, glucose, testosterone, PSA were checked. BMD was checked at the beginning of the treatment, after 2 years and after 5 years. All examinations were done with Whole-body densitometry Hologic Delphi - DXA. BMD was measured at lumbar spine and femoral neck. All men were treated with three-month i.m. injections of 1000 mg testosterone undecanoate. During the follow 
$577-580$

up-period, the level of testosterone in all the men was within the physiological range. The men were regularly checked according to the EAU guidelines (3). For statistic evaluation, we used nonparametric Wilcoxon test.

\section{Results}

Personal subjective evaluation of men by questionnaires: AMS Figure 1. showed a significant improvement: from 36.11 points at beginning it was improved to 33.42 after one year, than 31.06 after 2 years and still after 8 years results were better than at the beginning 33.59 points. Evaluation of erectal functions IIEF 5 Figure 2. showed an improvement: from 14.75 points at beginning to 15.5 after one year than 16.53 after 2 years and 15.35

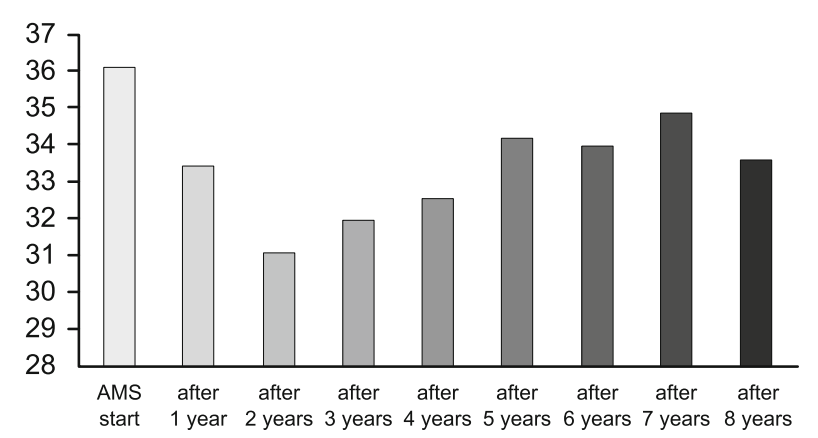

Fig. 1. Evaluation of ageing male scale (AMS).

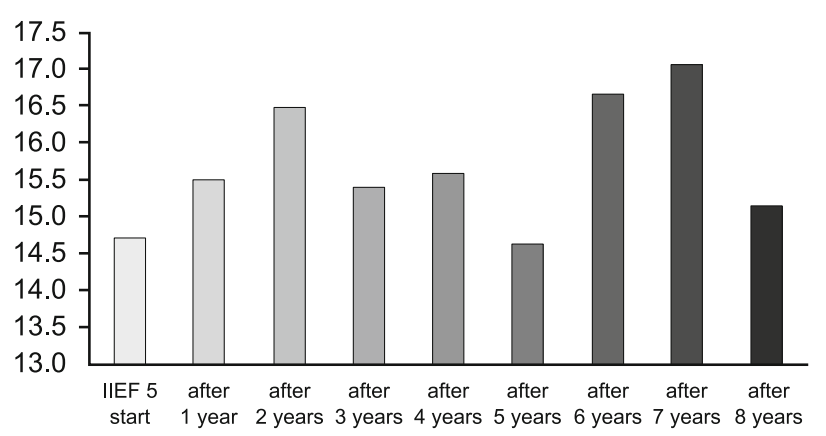

Fig. 2. Evaluation of Erectal functions International index of Erectal functions (IIEF 5).

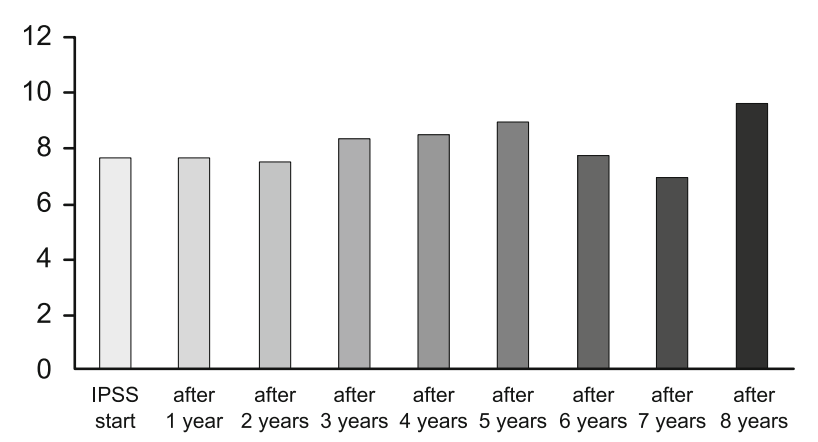

Fig. 3. Voiding functions International prostate symptom score IPSS (voiding part).

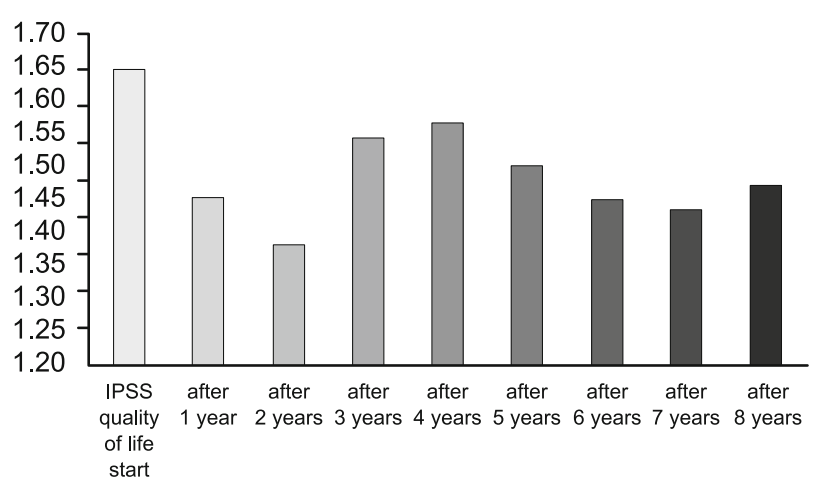

Fig. 4. IPSS Quality of life.

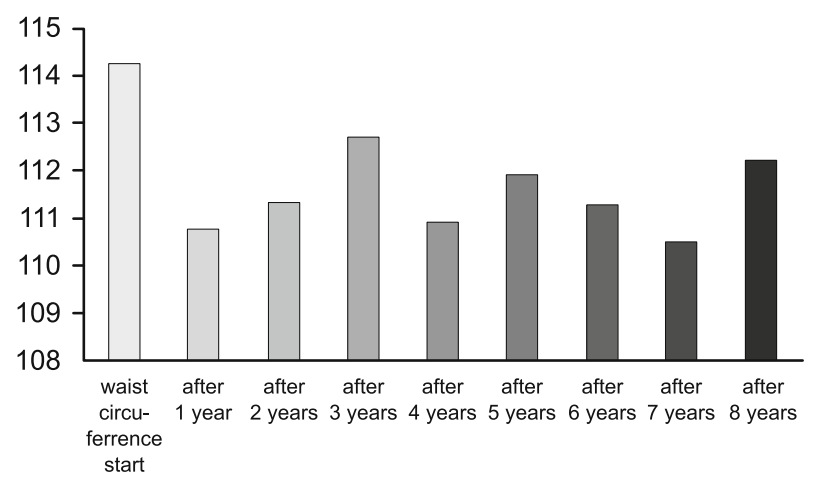

Fig. 5. Waist circumference.

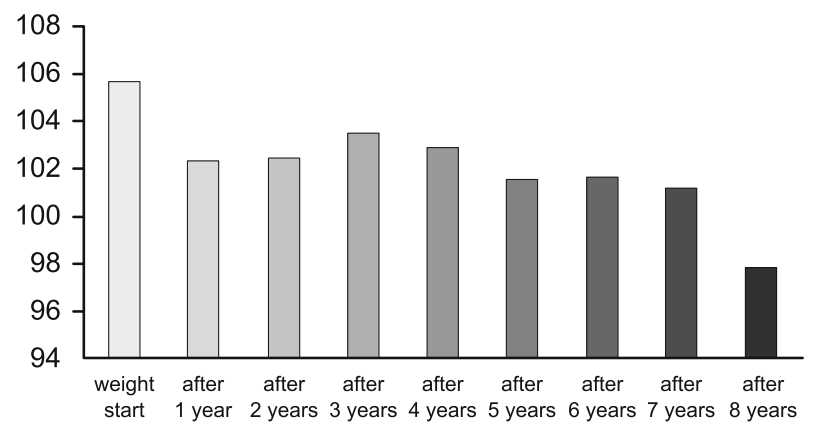

Fig. 6. Weight.

after 8 years, results were still better than at the beginning. Influence of TRT on voiding functions IPSS Figure 3, did not show significant changes, but the quality of life was improved Figure 4. Objective evaluations were: waist circumference Figure 5. and weigh Figure 6. Both parameters showed an improvement. Biochemistry: testosterone stimulates bone marrow and improves blood count. The level of Hemoglobin is shown in Figure 7. (14). Glucose (Fig. 8) levels were stable in most men, triglycerides (Fig. 9) slightly decreased, HDL cholesterol had stable levels. Testosterone level was in physiological ranges all the time (Fig. 10). PSA level was slightly increased (Fig. 11), in two men temporally above $4 \mathrm{nmol} / \mathrm{l}$. After the discontinuation of the treatment, it dropped back, and we continued in TRT. We found in both men 


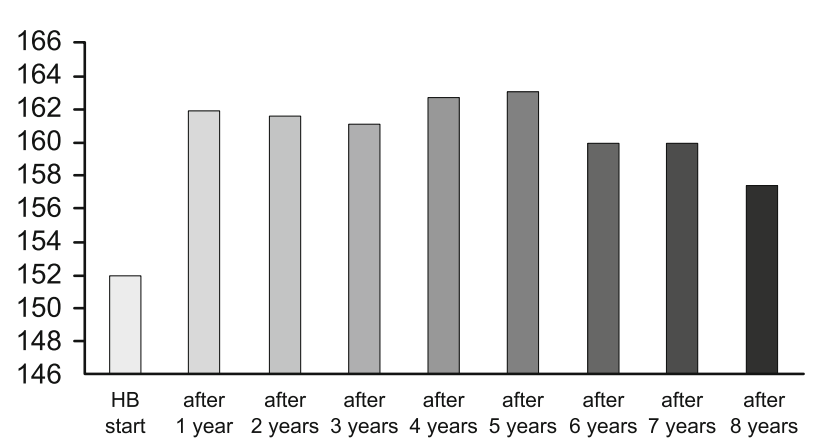

Fig. 7. Level of Hemoglobin.

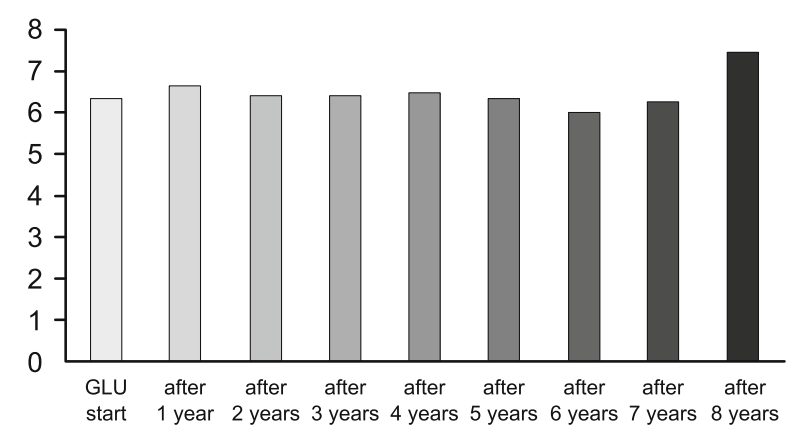

Fig. 8. Glucose level.

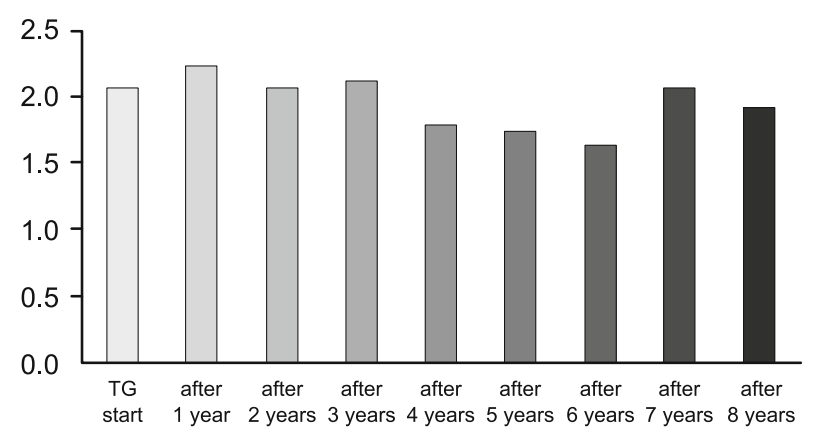

Fig. 9. Triglycerides.

chronic prostatitis. The prostate was soft and painful. In two men, we found a prostate cancer (PC). The results from bone mineral density of lumbar spine was during long term follow up significantly improved.

\section{Discussion}

Testosterone therapy ameliorates the symptoms of hypogonadism, decreases the risk for its negative sequelae, and can significantly improve the quality of life. Past fears of an increased PC risk persist. We diagnosed PC in 2 men. Recent studies do not support an increased risk for de novo prostate cancer, progression of the disease, or biochemical recurrence in hypogonadal men with a history of non-high-risk prostate cancer treated with testosterone therapy (4). Although it is clear that prostate cancer is exquisitely sensitive to changes in serum testosterone at low concentrations, there is a considerable evidence that prostate cancer growth becomes androgen indifferent at higher concentrations. The most likely mechanism for this loss of androgen sensitivity at higher testosterone concentrations is the limited capacity of the androgen receptor to bind androgen. This saturation model explains why serum testosterone appears unrelated to prostate cancer risk in the general population and why testosterone administration in men with metastatic prostate cancer causes a rapid progression in castrated, but not hormonally intact men (5). Worrisome features of prostate cancer such as high Gleason score, extracapsular disease and biochemical recurrence after surgery have been reported in association with low, but not high level of testosterone (5). In the study of safety, Feneley and Carruthers (2012) found fourteen new cases of prostate cancer after 2966 man-years of treatment. This represents the rate one diagnosed case of PC per 212 years. Time to diagnosis ranged from 1 to 12 years (mean 6.3 years). All tumors were clinically localized and suitable for potentially curative treatment. Initiating testosterone treatment had no statistically significant effect on total PSA, free PSA or free/total PSA ratio, and any initial PSA change had no predictive relationship to subsequent diagnosis of cancer. (6) Muller et al (2012) examined 4073 men with biopsy of prostate and conclusion was: Baseline serum testosterone (T) and dihydrotestosterone (DHT) levels were unrelated to PC detection or grade 7 (3). How Does Prostate Tissue Interact with Serum T? Sex hormones exert their effects at the periphery after binding to androgen receptors. Testosteron saturation in the prostatic tissue is extremely low. Studies carried out on humans, rats, and dogs prostates showed that serum $\mathrm{T}$ level

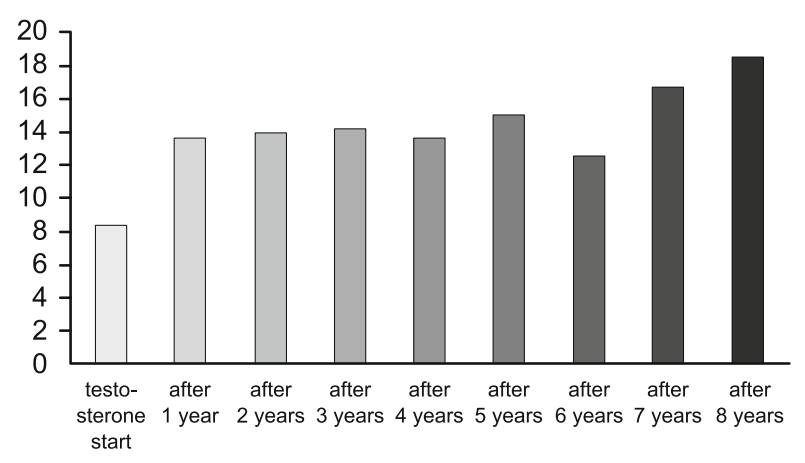

Fig. 10. Testosterone level.

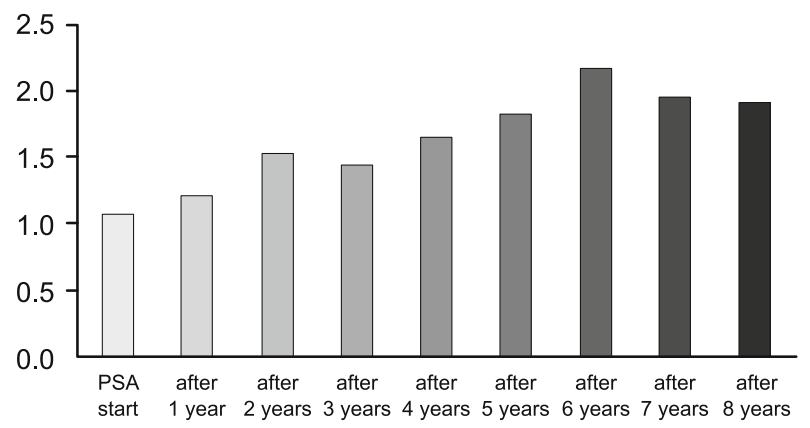

Fig. 11. PSA level. 


\section{$577-580$}

required for maximum androgen receptor binding is as low as 2 $-4 \mathrm{nM}(60-120 \mathrm{ng} / \mathrm{dL})(8,9)$. It is clear that this serum level is approximately half the level of $\mathrm{T}$ used in diagnosing late-onset hypogonadism (10). This finding indicates that prostate tissue is saturated with $\mathrm{T}$ even if its serum levels are extremely low, and this is explained by the saturation theory. According to this, serum $\mathrm{T}$ levels above this should not have any significant effect on the prostatic tissue (11). This assumption is also supported by a randomized, placebo-controlled clinical study by authors Atan et al (2013). This study showed that intra-prostatic levels of $\mathrm{T}$ and DHT and cell proliferation markers did not change although serum $\mathrm{T}$ level increased after exogenous $\mathrm{T}$ treatment in comparison with the placebo group. These data indicate that there is no direct correlation between serum $\mathrm{T}$ levels and intra-prostatic hormonal milieu (12). PC development is independent from endogenous serum $\mathrm{T}$ levels. TRT for symptomatic hypogonadism does not increase the risk of PC development (12).

\section{Conclusion}

There are more and more older men with abdominal obesity and other co-morbidity and low level of testosterone. TRT had multiple positive effect in these men. In our study, we proved very good results long term. Men felt better, had better erections, lost weight and also, waist circumference diminished. Blood count was improved and also bone mineral density of lumbar spine. Is important to check blood count and PSA. Besides of the mentioned results of TRT, we have observed a positive effect of this treatment on further parameters characterizing the quality of life: strength and endurance. Also, other psychological functions related to mentioned somatic improvements were positively influenced by TRT. Though mentioned subjective parameters were not evaluated quantitively (qualitative and quantitative analysis of subjective factors is demanding) the patients reported their benefits related to quality of life. Another advantage of treatment is that men on TRT have to be well monitored and the result was that we found 2 PC early stage.

\section{References}

1. Fillo J, Levčíkova M, Ondrušová M, Breza J, Labaš P. Importance of different Grades of abdominal Obesity on testosterone level, erectile dysfunction and clinical coincidence. Am J Men's Health 2017; 11(2): 240-245.

2. Fillo J, Breza J, Levčíková M, Luha J, Vachulova A, Durdík Š, Labaš P. Occurrence of erectile dysfunction, testosterone deficiency 3 syndrome and metabolic syndrome in patients 4 with abdominal obesity. Where is a sufficient level 5 of testosterone? Int Urol Nephrol 2012; 44: 1113-1120.

3. Muller RL, Gerber L, Moreira DM, Andriole G, Castro-Santamaria R, Freedland SJ. Serum testosterone and dihydrotestosterone and prostate cancer risk in the placebo arm of the Reduction by Dutasteride of Prostate Cancer Events trial. Eur Urol 2012; 62 (5): 757-764.

4. Nguyen TM, Pastuszak AW. Testosterone Therapy Among Prostate Cancer Survivors. Sex Med Rev 2016; 4 (4): 376-388. doi: 10.1016/j. sxmr.2016.06.005.
5. Morgentaler A. Testosterone therapy in men with prostate cancer: scientific and ethical considerations. J Urol 2013; 189 (Suppl 1): S26-33. doi: 10.1016/j.juro.2012.11.028.

6. Feneley MR, Carruthers M. Is testosterone treatment good for the prostate? Study of safety during long-term treatment. J Sex Med 2012; 9 (8): 2138-2149. doi: 10.1111/j.1743-6109.2012.02808.x.

7. Ho SM, Damassa D, Kwan PW, Seto HS, Leav I. Androgen receptor levels and androgen contents in the prostate lobes of intact and testosterone-treated Noble rats. J Androl 1985; 6 (5): 279-290.

8. Traish AM, Williams DF, Hoffman ND, Wotiz H. Validation of the exchange assay for the measurement of androgen receptors in human and dog prostates. Prog Clin Biol Res 1988; 262 (5): 145-160.

9. Wang C, Nieschlag E, Swerdloff R, Behre HM, Hellstrom WJ, Gooren LJ, Kaufman JM, Legros JJ, Lunenfeld B, Morales A, Morley JE, Schulman C, Thompson IM, Weidner W, Wu FC. Investigation, treatment, and monitoring of late-onset hypogonadism in males: ISA, ISSAM, EAU, EAA, and ASA recommendations.International Society of Andrology., International Society for the Study of Aging Male., European Association of Urology., European Academy of Andrology. American Society of Andrology. Eur Urol 2009; 55 (1): 121-130.

10. Morgentaler A. Testosterone replacement therapy and prostate cancer. Urol Clin North Am 2007; 34 (4): 555-563.

11. Marks LS, Mazer NA, Mostaghel E, Hess DL, Dorey FJ, Epstein JI, Veltri RW, Makarov DV, Partin AW, Bostwick DG, Macairan ML, Nelson PS. Effect of testosterone replacement therapy on prostate tissue in men with late-onset hypogonadism: a randomized controlled trial. JAMA 2006; 296 (19): 2351-2361.

12. Atan A, Tuncel A, Yesil S, ${ }^{1}$ and Balbay D. Serum Testosterone Level, Testosterone Replacement Treatment, and Prostate Cancer. Adv Urol 2013; 275945. doi: 10.1155/2013/275945 PMCID: PMC3789297.

13. Levčíkova M, Dubravický J, Breza J, Luha J, Labaš P, Fillo J. Testosterone replacement therapy (TRT) and its effect on bone marrow. How serious is it and is there a true polyglobulia? Bratisl Med J 2017; 118 (11): 654-657.

Received March 8, 2018. Accepted June 21, 2018. 